\title{
Following the Biosimilar Breadcrumbs: When Health Systems and Manufacturers Approach Forks in the Road
}

\author{
Sonia T. Oskouei, PharmD
}

\begin{abstract}
SUMMARY
Over 2 years have passed since the first biosimilar was approved for use in the United States. Despite a relatively slow start, biosimilar activity has significantly increased in recent months. Biologics are the most expensive drug category in the United States, costing patients hundreds or even thousands of dollars per year. Biosimilars have the potential to significantly decrease cost of care, increase access, and improve patient outcomes. In order to realize the potential savings, biosimilar manufacturers, health care providers, and payers must develop strategies to navigate the challenging health care environment and understand where and how biosimilars bring the most value to patients.

Trends in biosimilar uptake within health systems have demonstrated the need for manufacturers to deploy a robust product strategy before and after launch. In order to gain high-level insight from health system experiences with the first infliximab biosimilar approved in the United States, a questionnaire was distributed to pharmacy representatives from health systems during March and April 2017. Responses from more than 50 health systems across the country revealed that the key barriers and challenges faced with biosimilar uptake include payers and reimbursement, interchangeability, provider preference, and cost. This article explores health system experiences with biosimilars thus far and describes real-world implementation strategies. In addition, insights into manufacturer considerations are highlighted with regard to financial, clinical, and operational decisions.
\end{abstract}

J Manag Care Spec Pharm. 2017;23(12):1245-48

Copyright $\odot 2017$, Academy of Managed Care Pharmacy. All rights reserved.

$\mathrm{I}$ n 2016, 4 out of the 5 top drug expenditures in the United States were biologics that have competing biosimilars in the pipeline. ${ }^{1}$ In fact, each of the top 5 drug expenditures in clinics during the same year were biologics with biosimilars in development (Table 1). ${ }^{1}$ Biosimilars are approved by the U.S. Food and Drug Administration (FDA) based on evidence that they have no clinically meaningful differences as compared with the reference biologic in terms of safety and efficacy. ${ }^{2}$ These products have the potential to provide substantial cost savings for the U.S. health care market. So, why haven't all health systems rapidly converted to them?

It is well known that the U.S. health care system is very complex. The potential cost savings from biosimilars has been estimated to be $\$ 44.2$ billion dollars over a 10 -year time frame, yet there are many obstacles that manufacturers and health systems must overcome to truly realize the benefits. ${ }^{3}$ Manufacturers are faced with making key decisions from research and development to product launch strategies. Health systems are challenged with properly evaluating biosimilar products from a financial, clinical, and operational standpoint to ensure that the most cost-effective therapies are used. Based on the varied market trajectories of the first 2 biosimilars in the U.S. market (filgrastim and infliximab biosimilars), it is evident that each manufacturer decision has the potential to affect product uptake and use at the provider level. ${ }^{4}$

To gain insight from health system experiences with the first approved U.S. infliximab biosimilar, a brief questionnaire containing the following questions was created to understand costsavings perceptions, barriers, and institutional considerations:

1. What are the concerns or objections regarding infliximab biosimilar use at your health system?

2. Have there been conversations with payers to understand their positions on biosimilars?

3. Has the infliximab biosimilar been evaluated by the P\&T committee?

4. If the infliximab biosimilar were to be added to formulary, would it replace the reference product? If not, what would be the utilization criteria?

5. Is there a cost savings in using the infliximab biosimilar compared with the reference product in your organization (considering both inpatient and outpatient use)?

The questionnaire was distributed to health system pharmacy representatives, including vice presidents, directors, and clinical specialists, during March and April 2017. Based on responses from 57 health systems, financial, clinical, and operational insights were identified, revealing key areas for evaluation. For each area of focus, manufacturers must also be prepared to enter the market with robust strategies to address the potential barriers and concerns to support product use.

\section{Financial Considerations}

All health systems that responded to the questionnaire had used the reference infliximab product within their organizations. When asked about potential cost savings with the infliximab biosimilar, $76 \%$ of respondents perceived that there was a cost savings opportunity compared with the reference product. Many variables must be considered when analyzing the overall financial effect of a biosimilar on a health system. In fact, the type of biosimilar being evaluated plays a role in the equation, since biosimilars indicated for supportive care versus curative or disease management have potential varied scales of impact and payer implications. The provider setting in which the drug 


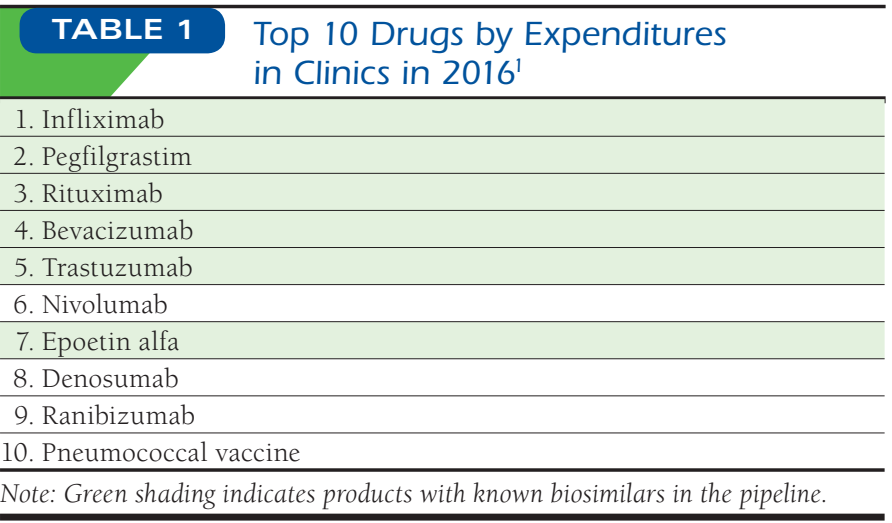

is administered also has implications, since acquisition costs and reimbursement models vary depending on sites of care. With an increasing number of biosimilars in the pipeline that are used in the outpatient setting, reimbursement continues to become the greater financial focus in the cost-savings equation.

Questionnaire responses revealed that the primary concern or barrier for using an infliximab biosimilar was payers or reimbursement (28\%), whereas a smaller percentage (10\%) listed cost as a barrier (Figure 1). Unlike small molecule generic drugs, which often obtain preferred positioning within payer formularies when approved, there is currently hesitancy from payers to promote disease-treating biosimilars for various reasons, including interchangeability and brand rebates. ${ }^{5}$ If a biosimilar was clinically supported by a health system, and the acquisition cost was $15 \%$ less than the reference product, lack of adequate payer coverage would still result in a significant barrier to product uptake. Approximately one third of health system respondents stated that they had conversations with payers to understand their stance on biosimilars, representing a great need for provider-payer relationships to ensure alignment of initiatives.

From a financial standpoint, health systems are tackling barriers through various implementation strategies. In the case of the infliximab biosimilar, as of the end of April 2017, 62\% of questionnaire respondents had not yet taken the product to their pharmacy and therapeutics (P\&T) committees. The most common reason for delay was financial uncertainty, with some pursuing a "wait and see" approach. For sites of care that approved formulary addition of the infliximab biosimilar, implementation strategies ranged from full product conversion to "new patients" only. Some sites added it to their formularies as a preferred product but only when payer coverage supported it. In addition, a few sites with their own health plans decided to delay the decision until the second infliximab biosimilar entered the market, in order to evaluate all 3 options (reference product and 2 biosimilars).

For manufacturers, the decision to enter the biosimilar space is a huge investment. A biosimilar can take approximately
10 years to develop and can cost up to $\$ 200$ million. ${ }^{6}$ In order to gain significant return on investments, manufacturers must develop robust pricing and payer strategies to drive market share. They must also be prepared to address and compete with brand market preservation strategies, including payer negotiations (to gain preferred formulary positioning), bundling products, and aggressive targeted pricing for high volume users. ${ }^{7}$

\section{Clinical Considerations}

Following financial barriers to payers and reimbursement, interchangeability and switching patient therapy were identified as the next greatest barrier to infliximab biosimilar uptake (20\%; Figure 1). When it comes to clinically evaluating a biosimilar, health systems are faced with making clinical recommendations without typical resources, such as extensive clinical trials. Based on the premise of the Biologics Price and Competition Act and the 351(k) pathway, biosimilars are approved via an abbreviated pathway that uses comparative data and publicly available information from the FDA's previous evaluation of the reference product to demonstrate biosimilarity to the reference product. ${ }^{2}$ This comparative protocol heavily focuses on analytical and physiochemical data of molecules versus clinical trials, which prove efficacy and safety as completed with the originator product. With highly similar physiochemical characteristics, manufacturers may extrapolate indications for a biosimilar to further cover those of the reference product, per totality of evidence. Therefore, health care providers are challenged with clinically evaluating biosimilars with a different lens.

A majority of health systems responded that they would keep the reference and the biosimilar infliximab products on formulary, if the biosimilar was to be approved through the P\&T committees. This strategy reflects the early stages of comfort by providers and patients, in addition to the variable payer landscape. Provider and patient preferences were identified as the third greatest barrier to biosimilar uptake by health systems (14\%), with immunogenicity and clinical safety highlighted, as well (6\%; Figure 1). Health systems continue to address these barriers through education of key stakeholders, with the topics of extrapolation, interchangeability, and the regulatory process for biosimilars. When it comes to biosimilar education, it is important to target the "four P's": providers, pharmacists, payers, and patients. Understanding how biosimilars are defined, created, and approved will allow health care providers and patients to make informed decisions when evaluating products.

Clinically, biosimilar manufacturers are faced with making key decisions regarding research and development, including study designs, indications, and interchangeability designation. The FDA defines an interchangeable biosimilar as a biosimilar that can be expected to produce the same clinical result as the reference product in any given patient. ${ }^{2}$ This means that 


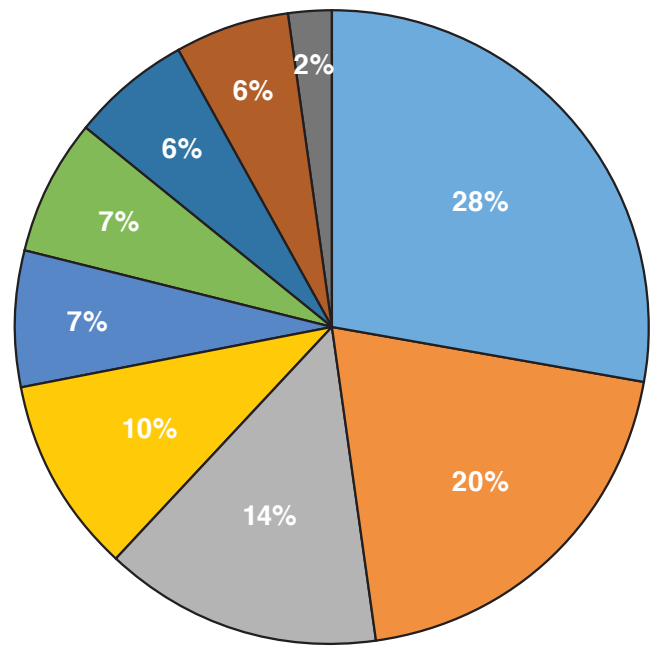

\begin{tabular}{|l|}
\hline Payer/reimbursement \\
Interchangeability/switching patients \\
Patient/provider preferences \\
Cost \\
340B \\
Brand rebate \\
Clinical safety/immunogenicity \\
None \\
Stocking multiple products
\end{tabular}

switching between the reference product and biosimilar has no greater risk in terms of safety and efficacy than using the reference product alone. ${ }^{2}$ A major result of interchangeability designation is that the biosimilar may be substituted for the reference product at the pharmacist level. ${ }^{2}$ With the extent of dollars and resources required to seek interchangeability, it is difficult to assess the value of the FDA interchangeability designation as it relates to "clinical confidence" by providers and the effect on product use. In addition, manufacturers must also target education for the "four P's" throughout the product's lifecycle, providing training material and access to clinical information such as international experiences and postmarketing studies.

\section{Operational Considerations}

In addition to financial and clinical considerations, health systems are faced with evaluating the operational effect of adding a biosimilar to formulary. From procurement to automation, adding a medication to a health system's formulary requires multiple steps. Health systems constantly work to streamline and standardize inventory, so if a decision is made to keep a biosimilar and reference product on formulary, additional steps may be required to ensure appropriate management of the products. In fact, a small percentage (2\%) of questionnaire respondents mentioned stocking multiple products as another barrier for infliximab biosimilar use (Figure 1). For example, the pharmacy inventory within health systems is often managed through designated gatekeepers, such as pharmacy technicians or procurement technicians, or it is self-managed by staff. A biosimilar and reference product must essentially be treated as sound-alike, look-alike products to ensure that they are built correctly in inventory management software and ordering platforms so as to minimize risk.
The "cost of change" or "cost of implementation" to operationalize a formulary decision regarding biosimilars must be considered as well. Health systems must evaluate whether the overall financial value of the biosimilar meets the organization's threshold for cost savings in order to dedicate the time and resources needed to implement the opportunity. For example, the time and resources needed to update information technology platforms or automation technology serve as "nondirect" costs of product implementation. Training and administrative work related to the billing of biosimilars may be needed, since the nonproprietary naming, unique product modifiers, and $\mathrm{J}$ code structure of biosimilars must be well understood to ensure accurate billing of each product.

From a manufacturer's standpoint, product accessibility and availability are critical to ensuring that health systems are able to procure the biosimilars readily and easily. If a biosimilar is only available through a specialty distribution channel, for example, it could require additional steps to procure, potentially leading to additional workload (and costs). As seen with the first 2 U.S. biosimilars, product distribution decisions can enhance or hinder product uptake. Biosimilar manufacturers must decide which distribution channels to use, realizing the potential effect that each path might have on health system operations and finances. In addition, with drug shortages affecting health systems on a daily basis, it is important for biosimilar manufacturers to ensure continuity of supply through good manufacturing practices to satisfy FDA regulations. These types of operational considerations become increasingly important when multiple biosimilars enter the market for the same reference product. Barring no or minimal financial differences, 
the operational components will potentially be the key drivers in order to differentiate manufacturers in the marketplace.

\section{Conclusions}

With increasing pressure to reduce the overall cost of health care, biosimilars have the potential to increase competition within the most expensive drug categories in the world. As the United States continues to gain experience with biosimilars, and as more products enter the market, health systems and manufacturers will be able to reflect on early successes and challenges to further develop biosimilar strategies. Financial, clinical, and operational considerations will continue to drive product decisions by providers. Ideally, the biosimilar movement afoot today will affect health care much like the introduction of generic drugs did years ago: increasing competition, driving down costs, and maintaining optimal patient outcomes.

\section{Authors}

SONIA T. OSKOUEI, PharmD, Premier, Charlotte, North Carolina.

AUTHOR CORRESPONDENCE: Sonia T. Oskouei, PharmD,

Director of Pharmacy Program Development-Biosimilars, Premier, 13034 Ballantyne Corp. Pl., Charlotte, NC 28277.

Tel.: 704.816.6067; E-mail: Sonia_Oskouei@premierinc.com.

\section{DISCLOSURES}

The author received no outside funding support and has nothing to disclose.

\section{ACKNOWLEDGMENTS}

The author acknowledges Christopher Jones, RPh—director, Pharmacy Automation \& Technology, Premier-for his feedback and review of the manuscript.

\section{REFERENCES}

1. Schumock GT, Li EC, Wiest MD, et al. National trends in prescription drug expenditures and projections for 2017. Am J Health Syst Pharm. 2017;74(15):1158-73.

2. Christl L. Overview of the regulatory pathway and FDA's guidance for the development and approval of biosimilar products in the United States. U.S.

Food \& Drug Administration. Available at: https://www.fda.gov/downloads/ advisorycommittees/committeesmeetingmaterials/drugs/arthritisadvisorycommittee/ucm513087.pdf. Accessed October 9, 2017.

3. Mulcahy AW, Predmore Z, Mattke S. The cost savings potential of biosimilar drugs in the United States. RAND Corporation. 2014. Available at: https://www.rand.org/content/dam/rand/pubs/perspectives/PE100/PE127/ RAND_PE127.pdf. Accessed October 9, 2017.

4. Blank C. How new biosimilars will impact the market. Drug Topics. February 15, 2017. Available at: http://drugtopics.modernmedicine.com/ drug-topics/news/how-new-biosimilars-will-impact-market. Accessed October 9, 2017.

5. Hakim A, Ross JS. Obstacles to the adoption of biosimilars for chronic diseases. JAMA. 2017;317(21):2163-64.

6. Burich M. Potential unintended consequences of CMS' policy for biosimilars reimbursement. Biosimilar Development. June 6, 2016. Available at: https://www.biosimilardevelopment.com/doc/potential-unintendedconsequences-of-cms-policy-for-biosimilars-reimbursement-0001. Accessed October 9, 2017

7. Helfand C. How did Johnson \& Johnson beat back Remicade's biosim? Call it the art of the deal. FiercePharma. July 20, 2017. Available at: http:// www.fiercepharma.com/pharma/what-s-behind-johnson-johnson-s-successful-remicade-defense-and-can-it-last. Accessed October 9, 2017. 